CLINICAL STUDY

\title{
Acute changes in endocrine and fluid balance markers during high-intensity, steady-state, and prolonged endurance running: unexpected increases in oxytocin and brain natriuretic peptide during exercise
}

\author{
Tamara Hew-Butler, Timothy D Noakes, Steven J Soldin ${ }^{1}$ and Joseph G Verbalis ${ }^{1}$ \\ University of Cape Town, Cape Town, 7725 South Africa and ${ }^{1}$ Georgetown University Medical Center, Washington, District of Columbia, USA \\ (Correspondence should be addressed to THew-Butler who is now at Systemic Inflammation Laboratory, Trauma Research, St Joseph's Hospital and Medical \\ Center, 350 West Thomas Road, Phoenix, Arizona 85013,USA; Email: tamara.hew@chw.edu)
}

\begin{abstract}
Maintenance of fluid homeostasis during periods of heightened physical stress can be best evaluated in humans using exercise as a model. Although it is well established that arginine vasopressin (AVP), aldosterone and atrial natriuretic peptide (ANP) are the principle hormones regulating fluid balance at rest, the potential contributions of other related endocrine factors, such as oxytocin (OT) and brain natriuretic peptide (BNP), have not been well described during exercise. Seven endurance-trained runners completed three separate running trials: a maximal test to exhaustion (high intensity), a 60-min treadmill run (steady state), and a $56 \mathrm{~km}$ ultramarathon (prolonged endurance exercise). Statistically significant pre- to post-run increases were found only following the ultramarathon in $[A V P]_{\mathrm{p}}(1.9$ vs $6.7 \mathrm{pg} / \mathrm{ml} ; P<0.05),[\mathrm{OT}]_{\mathrm{p}}(1.5 \mathrm{vs} 3.5 \mathrm{pg} / \mathrm{ml} ; P<0.05),[\mathrm{NT}-\mathrm{proBNP}]_{\mathrm{p}}(23.6$ vs $117.9 \mathrm{pg} / \mathrm{ml} ; P<0.01)$, [interleukin 6$]_{\mathrm{p}}$ (4.0 vs $\left.59.6 \mathrm{pg} / \mathrm{ml} ; P<0.05\right)$, [cortisol] $]_{\mathrm{p}}(14.6 \mathrm{vs} 32.6 \mu \mathrm{g} / \mathrm{ml}$; $P<0.01)$, [corticosterone $]_{\mathrm{p}}(652.8$ vs $3491.4 \mathrm{ng} / \mathrm{ml} ; \mathrm{P}<0.05)$ and $[11 \text {-deoxycortisol }]_{\mathrm{p}}(0.1$ vs $0.5 \mu \mathrm{g} / \mathrm{ml} ; P<0.05)$ while a significant post-run increase in [aldosterone] $]_{\mathrm{p}}$ was documented after high-intensity ( $4.9 \mathrm{vs} 12.5 \mathrm{ng} / \mathrm{ml} ; P<0.05)$, steady-state ( $6.1 \mathrm{vs} 16.9 \mathrm{ng} / \mathrm{ml} ; P<0.05$ ) and prolonged endurance running ( $2.6 \mathrm{vs} 19.7 \mathrm{ng} / \mathrm{ml} ; P<0.05$ ). Similarly, changes in fluid balance parameters were significantly different between the ultramarathon versus high-intensity and steady-state running with regard to plasma volume contraction (less \% contraction), body weight loss (increased \% weight loss), plasma $\left[\mathrm{Na}^{+}\right] \Delta$ (decreased from baseline), and urine osmolality $\Delta$ (increase from baseline). Hypothetically driven relationships between $[\mathrm{OT}]_{\mathrm{p}}$ and $[\mathrm{AVP}]_{\mathrm{p}}(r=0.69 ; P<0.01)$ and between [NTproBNP $]_{\mathrm{p}} \Delta$ and plasma $\left[\mathrm{Na}^{+}\right] \Delta(r=-0.79 ; \mathrm{P}<0.001)-$ combined with the significant and unexpected pre- to post-race increases after prolonged endurance exercise - allows for possible speculation that OT and BNP may assist their better known companion hormones (AVP and ANP) in the regulation of fluid balance during conditions of extreme physical stress.
\end{abstract}

European Journal of Endocrinology 159 729-737

\section{Introduction}

Arginine vasopressin (AVP), aldosterone and atrial natriuretic peptide (ANP) are commonly identified as the principle hormones regulating fluid balance in humans (1). During exercise, however, the relationships between these hormones with markers of fluid balance (2) become less predictable. The dissociations that are evident between the established steady-state relationships of AVP with plasma osmolality, aldosterone with plasma volume, and ANP with volume overload suggest that other endocrine factors - including cytokines that have also been proposed to affect fluid regulation (3) may also be involved with the regulation of fluid homeostasis during periods of heightened physical stress. Alternatively, these three fluid regulatory hormones may be influenced by perturbations from other regulatory systems during rigorous physical activity.

Mathematical modeling pathway analyses performed on a cohort of 82 runners participating in a $56 \mathrm{~km}$ footrace identified pre- to post-race changes in the plasma concentrations of oxytocin $\left([\mathrm{OT}]_{\mathrm{p}}\right)$, brain natriuretic peptide (BNP; [NT-proBNP $]_{\mathrm{p}}$ ), and corticosterone as accounting for $47 \%$ of the variance noted in corresponding changes in $[\mathrm{AVP}]_{\mathrm{p}}(4)$. Another statistically significant pathway identified [interleukin 6] [cortisol $]_{\mathrm{p}}$ and [corticosterone $]_{\mathrm{p}}$ as accounting for $21 \%$ of the variance noted in $[\mathrm{AVP}]_{\mathrm{p}}$ and $13 \%$ of the variance noted in the change in plasma sodium concentration $\left(\left[\mathrm{Na}^{+}\right]_{\mathrm{p}}\right)$ (4). Furthermore, a positive relationship was noted between $[\mathrm{AVP}]_{\mathrm{p}}$ and $[\mathrm{OT}]_{\mathrm{p}}$ as well as a curious 
$\sim$ fivefold pre- to post-race increase in $[\mathrm{NT}-\text { proBNP }]_{\mathrm{p}}$ despite a $\sim 9 \%$ decrease in plasma volume. These unexpected and intriguing findings - especially with regard to acute changes in plasma OT and BNP concentrations - prompted our interest to compare pre- to post-run changes of the same endocrine and fluid balance parameters under conditions of high-intensity and shorter duration running. We were particularly interested in: 1) whether or not changes in $[\mathrm{AVP}]_{\mathrm{p}}$ and $[\mathrm{OT}]_{\mathrm{p}}$ paralleled one another (a dual response to one stimulus) in alternative exercise conditions and 2) whether or not the increase in vascular hydrostatic pressure from high-intensity exercise would serve as greater stimulus (as would be expected) to NT-proBNP.

Therefore, the aim of this study was to investigate the acute endocrine changes during high-intensity, steady-state, and prolonged endurance running in seven well-trained runners who participated in our previous ultramarathon trial (4). More specifically, we were most interested in the relationships between markers of fluid balance (2) (plasma and urine $\left[\mathrm{Na}^{+}\right]$, plasma volume, and body weight) with those endocrine factors that were known (AVP (5), aldosterone (6)) or not known (OT (7), BNP (8), interleukin 6 (3), cortisol (9)) to be associated with the regulation of fluid homeostasis in humans during exercise. The exploratory and descriptive nature of this investigation served as a stepping stone to launch future, more mechanistic, studies involving the endocrine regulation of fluid balance during conditions of extreme physical stress.

\section{Methods}

\section{Subjects}

Seven well-trained endurance runners (five male and two female) who participated in the Two Oceans $56 \mathrm{~km}$ ultramarathon trial (4) were recruited to participate in the two additional laboratory trials and signed written informed consent for participation in this study, which was approved by both the Ethics Committee of the University of Cape Town and the Georgetown University Institutional Review Board. Ten subjects (five males and five females) were targeted, but only two females from the ultramarathon cohort volunteered for the follow-up laboratory studies.

\section{Testing protocol}

All seven runners participated in the Two Oceans $56 \mathrm{~km}$ ultramarathon (prolonged endurance running), held in Cape Town, South Africa on March 26, 2005. Baseline body weight, blood, and urine samples were obtained within 60 min of the start of the race. Postrace body weight, blood, and urine samples were obtained immediately upon race completion. Food and fluid intake were allowed ad libitum during the race.
Approximately, six months after completion of the prolonged endurance running race, all seven runners presented to the laboratory twice, 1 week apart, during the same morning hour to prevent individual diurnal variation between exercise tests. Each subject was asked to refrain from vigorous exercise $24 \mathrm{~h}$ prior to each test and consume a similar diet. No food or fluid was allowed during either laboratory treadmill running test. The ambient temperature in the laboratory for the two trials was $22-23{ }^{\circ} \mathrm{C}$; similar to the maximum temperature recorded during the $56 \mathrm{~km}$ footrace (4). Menstrual cycle phase was not controlled for in the two female runners: one of which was post-menopausal and the other oligomenorrheic. Neither female reported exogenous hormone ingestion.

A high-intensity $\left(\mathrm{VO}_{2} \max \right)$ exercise test was performed on the first visit to the laboratory. This test was of a maximal running test to volitional exhaustion on a motorized treadmill (Quinton type BA-1 treadmill, Bothell, WA, USA). Each athlete was allowed to warm up on the treadmill at a self-selected speed for $5 \mathrm{~min}$. After the completion of the warm-up, a heart-rate monitor (Polar Heart Rate Monitor, Lake Success, NY, USA) was fitted around each runner's chest and a mask tightly secured over the nose and mouth; in order to prevent air from escaping through the boundary of the mask. Oxygen uptake was measured continuously using an Oxycon Alpha Analyzer (Jaeger, Bilthoven, Netherlands) with maximal oxygen consumption $\left(\mathrm{VO}_{2}\right.$ maximum) defined as the highest value obtained in each subject before volitional exhaustion. The exercise protocol utilized was a peak treadmill running test, where each runner ran for $1 \mathrm{~min}$ at a speed of $7.5 \mathrm{~km} / \mathrm{hr}$. Thereafter, the speed was increased by $0.5 \mathrm{~km} / \mathrm{h}$ every $30 \mathrm{~s}$ until the subject could no longer keep pace with the treadmill (10). The last $30 \mathrm{~s}$ stage that was completed was designated as each athlete's peak treadmill running speed.

A steady-state treadmill test was performed in the laboratory 1 week later. Each subject ran for $60 \mathrm{~min}$ on the treadmill at a speed that corresponded to $60 \%$ of the peak treadmill running speed reached during the highintensity test.

\section{Sample collection and measurements}

Immediately prior to each exercise test, body weight was obtained on a calibrated Adamlab JPS electronic scale (Scales, Brackenfell, South Africa) in running attire and without shoes after the subject voided. A urine sample was obtained from this pre-race void. Venous blood was obtained with each subject in a seated position. Ten milliliters of venous blood were collected into chilled lithium heparin tubes and immediately centrifuged for $10 \mathrm{~min}$ at 3000 r.p.m. The separated plasma was immediately frozen at $-80{ }^{\circ} \mathrm{C}$ until further analysis could be performed. 
Within $5 \mathrm{~min}$ of completing each exercise test, all subjects returned to the seated position and $10 \mathrm{ml}$ of venous blood was collected into chilled lithium heparin tubes, centrifuged, separated, and frozen. Each subject voided and the urine was collected. Urine samples were immediately frozen and stored at $-80{ }^{\circ} \mathrm{C}$ until further analysis could be performed. A post-exercise body weight was then obtained.

\section{Analytical measurements}

Changes in plasma volume were estimated by comparing pre- and post-race measurements of plasma protein using a clinical refractometer (Schuco Clinical Refractometer 5711-2020, Japan). Plasma and urine sodium concentrations $\left(\left[\mathrm{Na}^{+}\right]\right)$were measured using ion-selective electrodes (Beckman Synchron EI-ISE, Fullerton, CA, USA).

\section{Hormone measurements}

Plasma levels of $\left([\mathrm{AVP}]_{\mathrm{P}}\right)$ and $\left([\mathrm{OT}]_{\mathrm{P}}\right)$ were measured by specific RIA following acetone-ether extraction as described previously (11). The standard curve for AVP is linear between 0.5 and $10.0 \mathrm{pg} /$ tube with the use of a synthetic AVP standard (PerkinElmer Life Sciences Inc., Boston, MA, USA). The minimum detectable concentration of AVP in extracted plasma was $0.5 \mathrm{pg} / \mathrm{ml}$. The AVP antiserum (R-4) displayed $<1 \%$ cross-reactivity with OT. The standard curve of the OT assay was linear between 0.25 and $5.0 \mathrm{pg} /$ tube with the use of a synthetic OT standard (PerkinElmer Life Sciences Inc.) The minimum detectable concentration of OT in extracted plasma was $0.25 \mathrm{pg} / \mathrm{ml}$. The OT antiserum (Pitt-Ab2) displayed $<1 \%$ cross-reactivity with AVP.

The plasma concentrations of two adrenal steroid hormones $\left.\left([\text { cortisol }]_{\mathrm{P}} \text { and [aldosterone }\right]_{\mathrm{P}}\right)$, and their two respective precursor hormones $\left([11 \text {-deoxycortisol }]_{\mathrm{p}}\right.$ and [corticosterone $]_{\mathrm{P}}$ ) were measured using a liquid chromatography-tandem mass spectrometer, in conjunction with an atmospheric pressure photoionization source, using methodology described previously (12).

Plasma BNP concentrations were assessed via measurement of the more stable cleaved inactive fragment, N-terminal pro-BNP ([NT-proBNP $\left.]_{\mathrm{P}}\right)$, using the automated Dade RxL Dimension as previously described (13). Plasma interleukin 6 ([IL6 $\left.]_{\mathrm{P}}\right)$ concentrations were measured by chemiluminescence (Immulite 1000 Diagnostic Product Corporation, Los Angeles, CA, USA).

\section{Statistical analysis}

All data were analyzed using the STATISTICA version 7 software (Stat Soft Inc., Tulsa, OK, USA). Comparisons between each exercise condition were made using a Student's $t$-test with and without plasma volume correction. Relationships between variables were assessed by linear regression analyses using Pearson's correlation coefficient. Where applicable, data are presented as means \pm s.E.M. Statistical significance was accepted when $P<0.05$. The change $(\Delta)$ in each designated variable was denoted by post-run minus pre-run measurements.

\section{Results}

The mean age of our seven subjects was $44 \pm 4$ years, training distance $56 \pm 6 \mathrm{~km} /$ week, and running experience $11 \pm 3$ years with an average $\mathrm{VO}_{2}$ max of $55 \pm 5 \mathrm{ml} / \mathrm{kg}$ per $\mathrm{min}$. The mean finishing time for the ultramarathon was $359 \pm 13$ min while the mean time to exhaustion for the $\mathrm{VO}_{2}$ max test was $10 \pm 1 \mathrm{~min}$.

Both plasma volume and body weight decreased immediately following all three running conditions (Fig. 1a and b). The estimated plasma volume $\Delta$ was largest following the $\mathrm{VO}_{2}$ max run $(-11 \pm 1 \%)$ and the smallest after the ultramarathon $(-8 \pm 0.0 \%)$. The plasma volume change after the ultramarathon was slightly but significantly less than the plasma volume change following both high-intensity and steady-state running $(-9 \pm 2 \%)$. Conversely, body weight $\Delta$ was largest following the ultramarathon $(-4 \pm 0.4 \%)$ compared with high-intensity $(-0.3 \pm 0.1 \%)$ and steady-state running $(-2 \pm 0.2 \%)$. The change in body weight between all three running conditions was statistically significant.

Plasma $\left[\mathrm{Na}^{+}\right] \Delta$ increased after both the high-intensity $(3 \pm 1 \mathrm{mmol} / \mathrm{l})$ and steady-state $(2 \pm 1 \mathrm{mmol} / \mathrm{l})$ runs, but decreased following the ultramarathon $(-4 \pm 2 \mathrm{mmol} / \mathrm{l}$; Fig. 1c). Conversely, urine osmolality $\Delta$ decreased following the high-intensity $(-43 \pm 45 \mathrm{mOsmol} / \mathrm{kg}$ $\left.\mathrm{H}_{2} \mathrm{O}\right)$ and steady-state $\left(-12 \pm 31 \mathrm{mOsmol} / \mathrm{kg} \mathrm{H}_{2} \mathrm{O}\right)$ runs, but increased markedly after the ultramarathon $\left(224 \pm 97 \mathrm{mOsmol} / \mathrm{kg} \mathrm{H} \mathrm{H}_{2} \mathrm{O}\right.$; Fig. 1d). The differences between the ultramarathon with both laboratory treadmill tests were statistically significant with regard to both of these fluid balance markers. Urine $\left[\mathrm{Na}^{+}\right] \Delta$ decreased following all three running tests, with the decrease after the steady-state run $(-41 \pm 13 \mathrm{mmol} / \mathrm{l})$ lower than that seen after the $\mathrm{VO}_{2}$ max test $(-7 \pm 6 \mathrm{mmol} / \mathrm{l} ; P<0.05)$ and the ultramarathon $(-11 \pm 24 \mathrm{mmol} / \mathrm{l}$; NS)

Comparisons between the three different running conditions (high-intensity, steady-state, and prolonged endurance) are shown in Tables 1 and 2. Significantly higher post-race and $\Delta$ values for $[\mathrm{OT}]_{\mathrm{p}}$, $[\mathrm{NT}-\mathrm{proBNP}]_{\mathrm{P}}$ $[\text { IL6 }]_{\mathrm{P}}$ and $[\text { cortisol }]_{\mathrm{p}}$ were noted following prolonged endurance exercise compared with the corresponding post-race and $\Delta$ values for high-intensity and steady-state running. Significantly higher pre-race, post-race and $\Delta$ values for $[\text { corticosterone }]_{\mathrm{P}}$ and $[11 \text {-deoxycortisol }]_{\mathrm{p}}$ were noted for prolonged endurance exercise compared with the corresponding pre-race, post-race and $\Delta$ values for high-intensity and steady-state running. The pre-race 

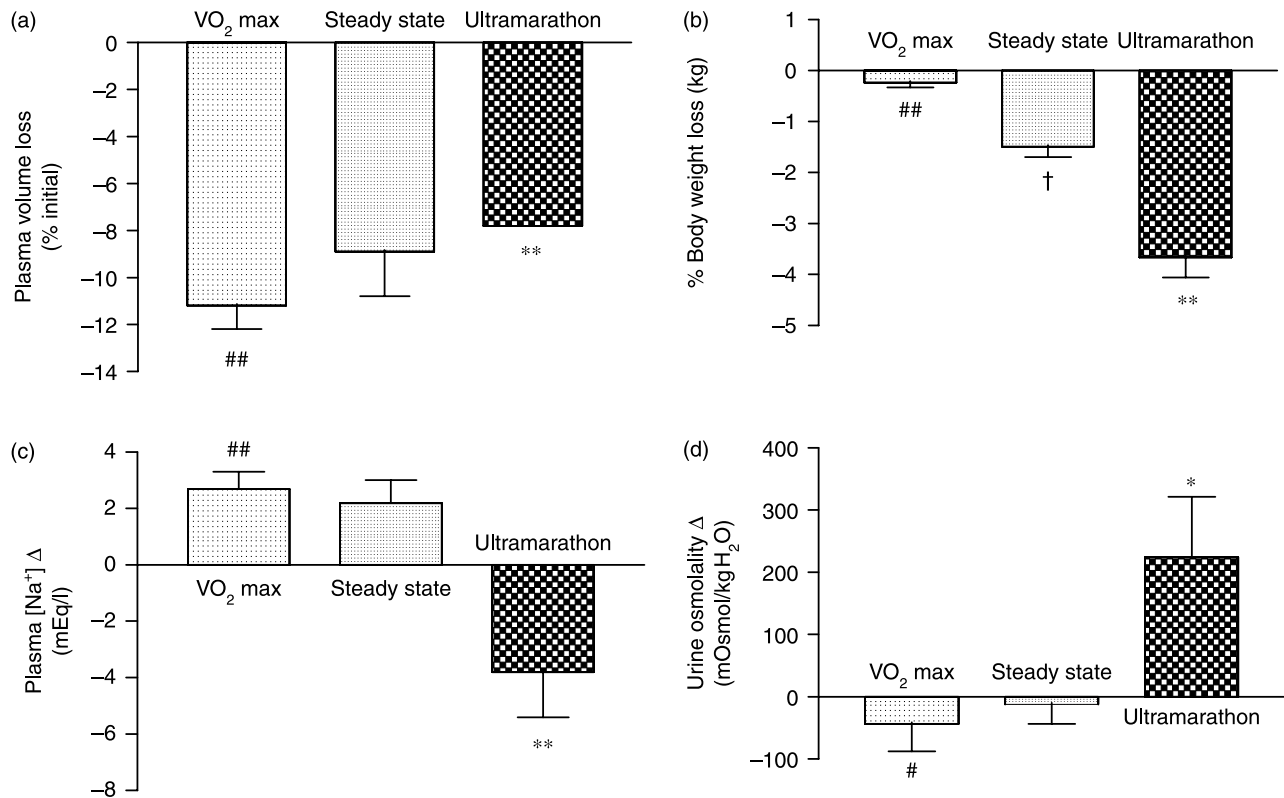

Figure 1 (a) Plasma volume changes between high-intensity, steady-state, and prolonged endurance running. (b) Body weight changes between high-intensity, steady-state, and prolonged endurance running. (c) Plasma $\left[\mathrm{Na}^{+}\right]$changes between high-intensity, steady-state, and prolonged endurance running. (d) Changes in urine osmolality between high-intensity, steady-state, and prolonged endurance running. For a-d: ${ }^{*} P<0.05,{ }^{* \star} P<0.01$ between steady state and ultramarathon. ${ }^{\#} P<0.05,{ }^{\# \#} P<0.01$ between $\mathrm{VO}_{2}$ max and ultramarathon. ${ }^{\dagger} P<0.01$ between $\mathrm{VO}_{2}$ max and steady state.

value for $[\mathrm{AVP}]_{\mathrm{P}}$ was significantly lower while $[\mathrm{AVP}]_{\mathrm{p}} \Delta$ was significantly higher in prolonged endurance running compared with only steady-state running. The level of statistical significance for all endocrine secretions measured remained identical when all post-run and $\Delta$ values were corrected for changes in plasma volume. Therefore, only the measured 'uncorrected' values are reported in this analysis.

Additional comparisons between pre- and post-run plasma hormone concentrations for $[\mathrm{AVP}]_{\mathrm{p}},[\mathrm{OT}]_{\mathrm{p}}$ and [aldosterone $]_{\mathrm{p}}$ are depicted in Fig. 2. The increase in plasma aldosterone concentrations from pre- to postrun were significant after all three running conditions (Fig. 2c). However, the plasma concentrations of AVP $(P<0.05)$, OT $(P<0.05)$, cortisol $(P<0.01)$, corticosterone $(P<0.05), 11$-deoxycortisol $(P<0.05)$, IL6 $(P<0.05)$, and NT-proBNP $(P<0.01)$ were significantly elevated from pre- versus post-race only following prolonged endurance running.

Exploratory linear relationships, which combined data points from the seven subjects participating in the three separate exercise trials for hypothetical purposes (seven subjects multiplied by three trials $=21$ total data points) suggested associations between $[\mathrm{OT}]_{\mathrm{p}}$ versus $[\text { AVP }]_{\mathrm{p}}(r=0.69 ; P<0.01$; Fig. 3$)$ and between $[\text { NT-proBNP }]_{\mathrm{p}} \quad \Delta$ versus $\left[\mathrm{Na}^{+}\right]_{\mathrm{p}} \quad \Delta \quad(r=-0.79$; $P<0.001$; Fig. 4).

The exploratory correlation between plasma post-race concentrations of OT versus vasopressin was further separated by exercise condition $(N=7)$ for illustrative purposes. Furthermore, data from the entire cohort of 82 runners participating in the ultramarathon trial (4) were included; embedding the seven data points (filled circles) of our seven subjects into the entire cohort data. A linear relationship $(r=0.57 ; P<0.0001)$ was observed when data points from all three trials $(N=96: 82$ data points from the ultramarathon, seven from the high-intensity run and seven from the steady-state run) were combined in this hypothetically driven analysis.

Table 1 Comparison between high-intensity, steady-state, and prolonged endurance running for plasma concentrations of neurohypophyseal, cytokine, and natriuretic peptides.

\begin{tabular}{lccc}
\hline & $\begin{array}{c}\text { Vo } \\
\text { (mean } \pm \\
\text { Variable }(\mathrm{pg} / \mathrm{ml})\end{array}$ & $\begin{array}{c}\text { Steady } \\
\text { state } \\
\text { (mean } \pm \\
\text { S.E.M.) }\end{array}$ & $\begin{array}{c}\text { S.E.M.) } \\
\text { Ultramarathon } \\
\text { (mean } \pm \text { S.E.M.) }\end{array}$ \\
\hline Vasopressin pre-run & $3.6 \pm 0.7$ & $3.1 \pm 0.3$ & $1.9 \pm 0.5^{*}$ \\
Vasopressin post-run & $14.4 \pm 5.2$ & $3.9 \pm 0.4$ & $6.7 \pm 1.4$ \\
Vasopressin $\Delta$ & $10.9 \pm 5.0$ & $0.7 \pm 0.3$ & $4.9 \pm 1.6^{*}$ \\
Oxytocin pre-run & $1.3 \pm 0.2$ & $1.1 \pm 0.3$ & $1.5 \pm 0.2$ \\
Oxytocin post-run & $2.6 \pm 0.7$ & $1.5 \pm 0.1$ & $3.5 \pm 0.5^{\dagger}$ \\
Oxytocin $\Delta$ & $1.3 \pm 0.7$ & $0.4 \pm 0.3$ & $2.0 \pm 1.0^{*}$ \\
NT-proBNP pre-run & $26.9 \pm 8.1$ & $18.4 \pm 4.6$ & $23.6 \pm 7.6$ \\
NT-proBNP post-run & $30.6 \pm 14.4^{\ddagger}$ & $26.6 \pm 6.2$ & $117.9 \pm 29.0^{\dagger}$ \\
NT-proBNP $\Delta$ & $3.7 \pm 6.6^{\S}$ & $8.1 \pm 3.1$ & $94.3 \pm 22.5^{\dagger}$ \\
IL6 pre-run & $4.0 \pm 0.0$ & $4.0 \pm 0.0$ & $4.0 \pm 0.0$ \\
IL6 post-run & $4.3 \pm 0.3^{\S}$ & $4.2 \pm 0.2$ & $59.6 \pm 9.8^{\dagger}$ \\
IL6 $\Delta$ & $0.3 \pm 0.3^{\S}$ & $0.1 \pm 0.1$ & $55.6 \pm 9.8^{\dagger}$ \\
\end{tabular}

${ }^{\star} P<0.05,{ }^{\dagger} P<0.01$ between steady state and ultramarathon. ${ }^{\ddagger} P<0.05$, ${ }^{8} P<0.01$ between $\mathrm{VO}_{2}$ max and ultramarathon. 
Table 2 Comparison between high-intensity, steady-state, and prolonged endurance running for plasma concentrations of mineralocorticoid and glucocorticoid steroid hormones.

\begin{tabular}{lccc}
\hline Variable & VO $_{\mathbf{2}}$ max $($ mean \pm S.E.M.) & Steady state (mean \pm S.E.M.) & Ultramarathon (mean \pm S.E.M.) \\
\hline Aldosterone pre-run $(\mathrm{ng} / \mathrm{ml})$ & $4.9 \pm 0.5$ & $6.1 \pm 1.9$ & $2.6 \pm 1.2$ \\
Aldosterone post-run $(\mathrm{ng} / \mathrm{ml})$ & $12.5 \pm 1.9$ & $16.9 \pm 2.7$ & $19.7 \pm 6.2$ \\
Aldosterone $\Delta(\mathrm{ng} / \mathrm{ml})$ & $7.6 \pm 2.3$ & $10.8 \pm 2.5$ & $17.1 \pm 6.1$ \\
Cortisol pre-run $(\mu \mathrm{g} / \mathrm{ml})$ & $11.6 \pm 2.4$ & $11.3 \pm 2.3$ & $14.6 \pm 1.7$ \\
Cortisol post-run $(\mu \mathrm{g} / \mathrm{ml})$ & $15.9 \pm 3.0^{\S}$ & $10.4 \pm 1.0$ & $32.6 \pm 4.3^{\dagger}$ \\
Cortisol $\Delta(\mu \mathrm{g} / \mathrm{ml})$ & $4.4 \pm 1.5^{\ddagger}$ & $-0.9 \pm 2.3$ & $17.6 \pm 4.5^{\dagger}$ \\
Corticosterone pre-run $(\mathrm{ng} / \mathrm{ml})$ & $170.7 \pm 68.6^{\ddagger}$ & $139.6 \pm 61.0$ & $652.8 \pm 183.3^{*}$ \\
Corticosterone post-run $(\mathrm{ng} / \mathrm{ml})$ & $518.9 \pm 187.5^{\ddagger}$ & $226.2 \pm 60.0$ & $3491.4 \pm 978.8^{\dagger}$ \\
Corticosterone $\Delta(\mathrm{ng} / \mathrm{ml})$ & $348.2 \pm 153.6^{\ddagger}$ & $86.6 \pm 74.0$ & $2838.6 \pm 872.8^{\dagger}$ \\
11-deoxycortisol pre-run $(\mu \mathrm{g} / \mathrm{ml})$ & $0.03 \pm 0.01^{\ddagger}$ & $0.03 \pm 0.01$ & $0.10 \pm 0.03^{*}$ \\
11-deoxycortisol post-run $(\mu \mathrm{gg} / \mathrm{ml})$ & $0.10 \pm 0.03^{\ddagger}$ & $0.05 \pm 0.01$ & $0.54 \pm 0.17^{\star}$ \\
11-deoxycortisol $\Delta(\mu \mathrm{g} / \mathrm{ml})$ & $0.06 \pm 0.03^{\ddagger}$ & $0.02 \pm 0.01$ & $0.44 \pm 0.16^{*}$ \\
\hline
\end{tabular}

${ }^{\star} P<0.05,{ }^{\dagger} P<0.01$ between steady state and ultramarathon. ${ }^{\ddagger} P<0.05,{ }^{\S} P<0.01$ between $\mathrm{VO}_{2}$ max and ultramarathon.

\section{Discussion}

It is clear from the results of this study that $\sim 6 \mathrm{~h}$ of prolonged endurance running elicits a statistically significant endocrine response that is not replicated
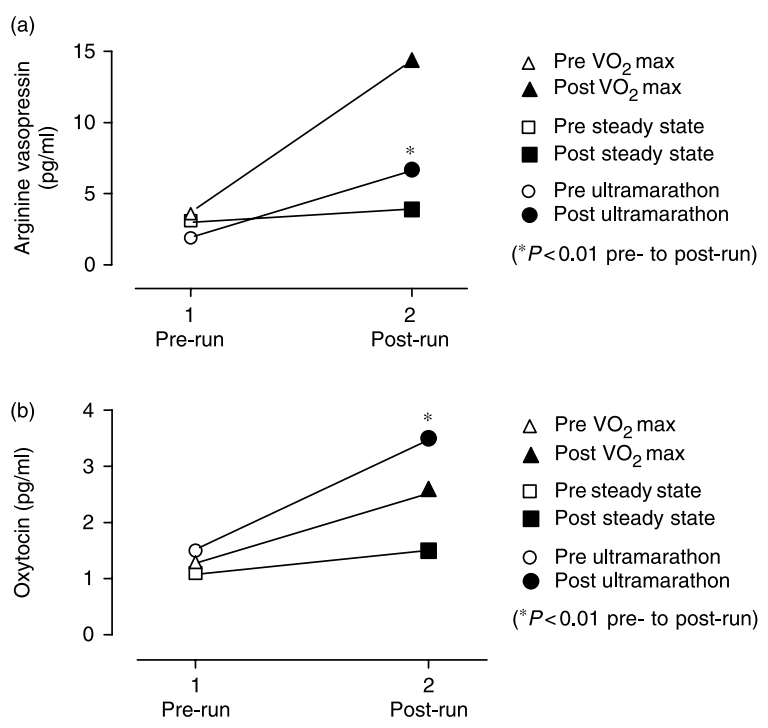

$\triangle$ Pre $\mathrm{VO}_{2} \max$

$\Delta$ Post $\mathrm{VO}_{2}$ max

$\square$ Pre steady state

- Post steady state

- Pre ultramarathon

- Post ultramaratho

( ${ }^{*} P<0.01$ pre- to post-run)

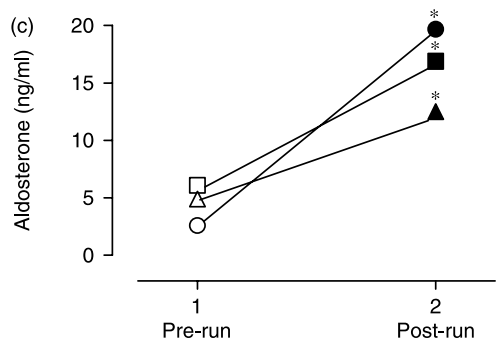

$\triangle$ Pre $\mathrm{VO}_{2} \max$

$\Delta$ Post $\mathrm{VO}_{2} \max$

$\square$ Pre steady state

- Post steady state

Pre ultramarathon

- Post ultramarathon

$\left({ }^{*} P<0.05\right.$ pre- to post-run)

Figure 2 (a) Changes in plasma AVP concentrations between high-intensity, steady-state, and prolonged endurance running.

(b) Changes in plasma OT concentrations between high-intensity, steady-state, and prolonged endurance running. (c) Changes in plasma aldosterone concentrations between high-intensity, steady-state, and prolonged endurance running. following either $\sim 10 \mathrm{~min}$ of high-intensity or $60 \mathrm{~min}$ of steady-state running (Tables 1 and 2; Fig. 2). The added psychological stress of participating in a $56 \mathrm{~km}$ ultramarathon can also be inferred by the elevated pre-race plasma concentrations of cortisol, corticosterone and 11-deoxycortisol; suggestive of heightened stimulation of the adrenal cortex in anticipation of the competitive event only (Table 2). The pre-race elevation in plasma cortisol concentration may have also been influenced by diurnal variation, although all three testing sessions occurred during the morning hours. Conversely, pre-race plasma AVP concentrations were lower prior to the ultramarathon compared with the $\mathrm{VO}_{2}$ max and steady-state laboratory runs. This raises the possibility that the subjects were overhydrated prior to the start of the 'competitive' ultramarathon, as opposed to before the 'non-competitive' treadmill runs, perhaps as a pre-race ritual again guided by psychological rather than physiological stimuli. The $0.9 \mu \mathrm{g} / \mathrm{ml}$ decrease in [cortisol $]_{\mathrm{p}}$ following $60 \mathrm{~min}$ of steady-state running confirms the high level of fitness alluded to in the demographic profile for these seven runners and further accentuates the profound physiological stress incurred in well-trained athletes participating in a $56 \mathrm{~km}$ foot race.

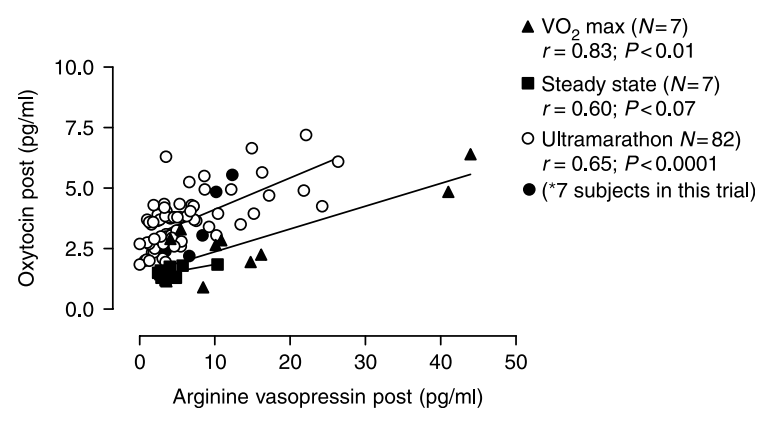

Figure 3 Correlations between pre- and post-run plasma oxytocin and plasma arginine vasopressin concentrations for combined data from three studies (total combined $N=96: r=0.57 ; P<0.0001$ ). 


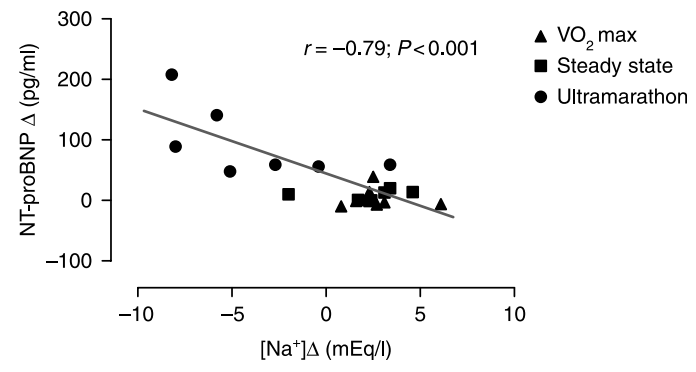

Figure 4 Correlation between the change in plasma sodium concentration and the change in NT-proBNP (post- minus pre-race) when all three exercise conditions are hypothetically combined for the seven subjects $(N=21)$.

The acute changes in the measured markers of fluid balance also reflect statistically significant changes following the ultramarathon compared with both high-intensity and steady-state running (Fig. 1). Plasma volume contraction was greatest following the $\mathrm{VO}_{2} \max$ test and least following the ultramarathon (Fig. 1a). This trend was reversed for \% body weight loss, with the greatest loss in body weight occurring after the ultramarathon with no appreciable body weight loss following the $\mathrm{VO}_{2}$ max test (Fig. 1b). This opposing trend would suggest that during exercise (non-steady state), body weight loss does not reflect parallel changes in plasma volume (2), unlike in the clinical (steadystate) scenario where body weight loss is considered reflective of hypovolemia and fluid status (14). It has been previously verified that the magnitude of plasma volume contraction is linearly related to exercise intensity (15) that would help explain the decreasing order of magnitude of \% plasma volume contraction following the high-intensity, steady-state and prolonged endurance runs. Conversely, the increasing magnitude of body weight loss following the $\mathrm{VO}_{2}$ max, steady-state, and ultramarathon runs is more likely due to metabolic factors such as substrate loss and muscle breakdown (16) that would logically contribute to increasing body weight loss - not reflective of pure fluid loss - over total exercise time.

Similarly, the corresponding decrease in plasma $\left[\mathrm{Na}^{+}\right] \Delta$ following the ultramarathon seemed to be opposed by an increase in urine osmolality $\Delta$ (Fig. 1c and d). These mirrored relationships seen in all three exercise conditions seemed to logically reflect: 1) enhanced solute conservation in dynamic response to decreasing plasma $\left[\mathrm{Na}^{+}\right]$during prolonged endurance running and 2) decreased solute excretion in response to increasing plasma $\left[\mathrm{Na}^{+}\right]$during both high-intensity and steady-state exercise. The endocrine mediators responsible for these expected alterations in fluid balance parameters, however, could not be determined by these descriptive results.

Of the two posterior pituitary hormones, AVP is widely regarded as the principle regulator of body water homeostasis (17). During high-intensity exercise, the fourfold pre- to post-run increase in $[A V P]_{\mathrm{p}}$ was accompanied by only a $\sim 3 \mathrm{mmol} / \mathrm{l}$ increase in plasma $\left[\mathrm{Na}^{+}\right]$. Thus, the change in $[\mathrm{AVP}]_{\mathrm{p}}$ largely exceeded any predicted osmotic response (18) and may be reflective of either concomitant non-osmotic stimuli and/or an appreciably enhanced osmotic response to maximal intensity exercise. This highly variable and substantial increase in AVP, might therefore suggest the inclusion of 'non' or 'high' responders in our well-trained cohort of runners that has been reported elsewhere $(19,20)$. 'Highresponders' are characterized by: 1) a resistance to glucocorticoid suppression by the administration of dexamethasone, 2) a higher corticotropin (ACTH) response following exercise, 3) an enhancement of AVP secretion with administration of dexamethasone, and 4) a higher plasma ACTH response after AVP infusion (20). It is hypothesized that 'high responders' have an enhanced hypothalamic drive to AVP secretion (20), with the wide variability in the response of the hypothalamic-pituitaryadrenal (HPA)-axis primarily related to the magnitude of AVP release (18). Administration of gamma-aminobutyric acid (GABA) agonists (sodium valproate (21) or alprazolam (22)) abolishes the AVP response to high-intensity exercise in humans, while administration of a GABA antagonist (DHEA) (22) increases the AVP-ACTH-cortisol response. These findings suggest that an osmotic/hypovolemic stimulus primarily controls AVP release during exercise $(21,22)$, despite the apparent dissociation that occurs in some individuals at maximal exercise intensities.

Alternatively, non-osmotic stimulation of AVP secretion has been hypothesized to occur during prolonged endurance exercise from significant $(\sim 9 \%)$ plasma volume contraction perhaps combined with stimulation by other endocrine mediators released during exercise (4). The likelihood that non-osmotic stimuli override the osmotic regulation of AVP during prolonged endurance running seems further evident from the $\sim 5 \mathrm{pg} / \mathrm{ml}$ increase in $[\mathrm{AVP}]_{\mathrm{p}}$ despite the $\sim 4 \mathrm{mmol} / \mathrm{l}$ decrease in $\left[\mathrm{Na}^{+}\right]_{\mathrm{p}}$ documented in these seven subjects following the ultramarathon. Therefore, it seems apparent that during both high-intensity and prolonged endurance running, non-osmotic or enhanced osmotic stimulation of AVP secretion may likely occur with large inter-individual variation.

The 'other' posterior pituitary hormone, OT, has been shown to participate in the regulation of sodium balance in animals (23), but seemingly not in humans (24). However, few studies have measured OT in humans during exercise. The only study documenting an increase in plasma OT concentrations following exercise studied five well-trained males running on a treadmill for $\sim 60 \mathrm{~min}$ at an intensity of $80 \%$ of $\mathrm{VO}_{2}$ max (7). Peak levels of OT ranged between 4.5 and $23.9 \mathrm{pg} / \mathrm{ml}$ and were elevated in three of the five runners. By contrast, OT did not change following highintensity exercise in male cyclists exercising for 20-25 min until exhaustion (25), or in healthy females during 20 min of graded exercise up to $90 \% \mathrm{VO}_{2} \max$ 
(26). These aggregated findings suggest that OT may not be stimulated by short-duration high-intensity exercise, but may be stimulated by continuous exercise activity lasting $\geq 60 \mathrm{~min}$. This suggestion is partially supported by our results, where plasma OT concentrations were significantly elevated after prolonged endurance, but not after steady-state running (Table 1; Fig. 2b).

The magnitude and pattern of change in $[\mathrm{OT}]_{\mathrm{P}}$ between high-intensity, steady-state, and prolonged endurance exercise did not parallel the changes noted for $[A V P]_{P}$ (Fig. 2a and b). These findings support an independent secretion of both posterior pituitary hormones in response to different exercise conditions, and infer that the regulation of $[\mathrm{AVP}]_{\mathrm{p}}$ during exercise may be independent of $[\mathrm{OT}]_{\mathrm{p}}$. Independent secretion of AVP and OT has been previously recorded in humans after chronic dehydration and sodium loading (27), and in assessments of diurnal variation (7). Despite the apparent dissociation in mean magnitude that was seen in our subjects from pre- to post-race (Fig. 2a and b), a linear association was noted between post-run $[\mathrm{AVP}]_{\mathrm{P}}$ and $[\mathrm{OT}]_{\mathrm{P}}$ when data from all three exercise conditions were hypothetically combined (Fig. 3). A significant positive correlation between the two hormones has also been documented in rats, and has been shown to remain robust under dissimilar stimuli such as hypovolemia, hyperosmolality, hypotension, uremia, and nausea.

The physiological stimulus and potential role for OT secretion in humans during prolonged endurance running are unclear. Although it is well documented that OT causes a natriuresis under physiological concentrations in male rats (23), evidence supporting a natriuretic effect of OT in humans is conflicting $(24,28,29)$. OT, like AVP, can cause an antidiuresis in humans (30) that is likely mediated by vasopressin V2 receptors in the collecting duct of the kidney (31). However, the dose of OT required to stimulate an equivalent antidiuresis is $\sim 100$-fold the amount of AVP (28). Further, more detailed, studies are required to elucidate the mechanisms involved in $[\mathrm{OT}]_{\mathrm{p}}$ stimulation - which may or may not be independent of stimuli to $[\mathrm{AVP}]_{\mathrm{p}}$ - to clarify if OT is associated in any way with fluid homeostasis in humans during exercise.

The statistically significant increase in BNP following prolonged endurance exercise is also unexpected (Table 1). While the role of ANP in the regulation of fluid balance during exercise has been widely evaluated (1), the role of BNP in fluid homeostasis has not (8). BNP is considered a marker of fluid overload (32), and has been measured after exercise primarily as an indicator of cardiac dysfunction (33). The significant increase in $[\mathrm{NT}-\text { proBNP }]_{\mathrm{P}}$ that is seen in our subjects following prolonged endurance exercise, but not highintensity or steady-state exercise, has been noted previously (33). Because [NT-proBNP $]_{\mathrm{P}}$ was not significantly elevated after the $\mathrm{VO}_{2}$ max test (where blood pressure, heart rate, and cardiac output would be the highest (34)) but is increased fourfold after the ultramarathon (where mean arterial pressure and left ventricular diameter are significantly reduced (35)), it appears that stimuli apart from the cardiovascular system may be responsible for the increase in BNP seen after prolonged endurance exercise. Whether BNP secretion is alternatively stimulated by inflammation (36), decreased renal blood flow (37), lipolysis (38), or from a yet to be determined factor under these conditions remains to be evaluated.

A highly speculative role for BNP in the regulation of fluid homeostasis during exercise is cautiously suggested by the exploratory and somewhat crude association between $[\mathrm{NT}-\mathrm{proBNP}]_{\mathrm{p}} \Delta$ and $\left[\mathrm{Na}^{+}\right]_{\mathrm{p}} \Delta$ (Fig. 4). Although this relationship reflects cumulative individual data across three separate exercise trials, the possibility that increased plasma BNP concentrations may result in a corresponding decrease in plasma $\left[\mathrm{Na}^{+}\right]$ seems plausible given the natriuretic property characteristic of this particular group of peptides. Therefore, the combined preliminary disassociation between BNP and maximal ventricular stimulation (high-intensity running to exhaustion) and possible association between $[\mathrm{NT} \text {-proBNP }]_{\mathrm{p}}$ and $\left[\mathrm{Na}^{+}\right]_{\mathrm{p}}$ during conditions of extreme physical stress opens the possibility that BNP may play at least a secondary role in the maintenance of fluid homeostasis during prolonged endurance exercise.

The statistically significant increase in the secretion of the mineralocorticoid hormone, [aldosterone $]_{\mathrm{P}}$, following all three running conditions is a welldocumented physiological response (39) (Fig. 2c). These collective data suggest that aldosterone secretion is rapid, predictable and consistent following exercise, and confirms that aldosterone is associated with the regulation of fluid balance during periods of heightened physical stress to assist with both sodium conservation and blood pressure maintenance (39).

Plasma concentrations of the precursor hormone to aldosterone, corticosterone, did not reflect concomitant changes in the magnitude of aldosterone secretion (Table 2). Although corticosterone is not known to play a significant role in any physiological process in humans (40), the significant elevations documented before and after prolonged endurance running, compared with high-intensity and steady-state running (Table 2), are notable. Furthermore, the fivefold elevations in corticosterone before and after the ultramarathon infer heightened stimulation of the adrenal cortex by ACTH. The corresponding sevenfold increase in plasma aldosterone concentrations, however, suggest the potentiation of aldosterone synthase activity in the adrenal gland to accelerate aldosterone formation during periods of heightened physical stress.

Statistically significant elevations in both [IL6 $]_{\mathrm{P}}$ (Table 1) and $[\text { cortisol }]_{\mathrm{P}}$ (Table 2) following the ultramarathon highlights the pronounced inflammatory and stress imposed by prolonged endurance 
running. However, a participatory role for cortisol and IL6 secretion in overall fluid balance is not apparent from these data.

\section{Limitations}

The unequal number of males and females preclude a more complete gender analysis between the three trials. However, three additional female marathon runners (who did not participate in the 2005 ultramarathon study) did participate in the two laboratory trials (highintensity and steady-state runs) and subsequent gender analysis comparing the two laboratory trials for five male and five female subjects did not find any statistical difference between any of the variables measured (data unpublished). Furthermore, gender analysis within a larger cohort (82 subjects) participating in the 2005 ultramarathon trial did not document significant pre- or post-race gender differences in any of the simultaneously measured endocrine or fluid balance parameters (4). Therefore, we feel that the inclusion of males and females into one unified group for comparison was physiologically appropriate. We also acknowledge that these observations can only create new hypotheses rather than solve mechanistic questions given the small sample size and descriptive nature of this study. However, we feel that these exploratory data open new avenues for investigation in regards to the potential role for OT and BNP in fluid regulation - and perhaps dysregulation - in exercising humans.

In summary, $\sim 6 \mathrm{~h}$ of prolonged endurance running elicit a significant pre- to post-run increase in $[A V P]_{p}$, $[\mathrm{OT}]_{\mathrm{p}},[\mathrm{NT}-\text { proBNP }]_{\mathrm{p}}, \quad[\text { interleukin } 6]_{\mathrm{p}}, \quad[\text { cortisol }]_{\mathrm{p}}$, [corticosterone $]_{\mathrm{p}}$ and [11-deoxycortisol $]_{\mathrm{p}}$ while a significant post-run increase in [aldosterone $]_{\mathrm{p}}$ was documented after high-intensity, steady-state, and prolonged endurance running. Similarly, changes in fluid balance parameters were significantly different between the ultramarathon and high-intensity and steady-state running with regard to plasma volume contraction (less \% contraction), body weight loss (increased \% weight loss), plasma $\left[\mathrm{Na}^{+}\right] \Delta$ (decreased from baseline), and urine osmolality $\Delta$ (increase from baseline). In conclusion, hypothetically driven relationships between $[\mathrm{OT}]_{\mathrm{p}}$ and $[\mathrm{AVP}]_{\mathrm{p}}$ and between $[\mathrm{NT}-\text { proBNP }]_{\mathrm{p}} \Delta$ and plasma $\left[\mathrm{Na}^{+}\right] \Delta-$ combined with significant and unexpected increases after prolonged endurance exercise - allows for possible speculation that OT and BNP may assist their better known companion hormones (AVP and ANP) in the regulation of fluid balance during conditions of extreme physical stress.

\section{Declaration of interest}

The authors declare that there is no conflict of interest that could be perceived as prejudicing the impartiality of the research reported.

\section{Funding}

This study was supported by a research grant from Astellas Pharma US, Inc., Deerfield, IL, USA and by Grant M01RR-023942-01 from the National Center for Research Resources (NCRR), a component of the National Institutes of Health (NIH). Its contents are solely the responsibility of the authors and do not necessarily represent the official views of NCRR or NIH.

\section{Acknowledgements}

The authors wish to thank Yoshihisa Sugimura MD, PhD and Ying Tian MD, PhD for their assistance with the AVP and OT assays, and Jonathan Dugas PhD, Lara Dugas PhD and Ross Tucker PhD for their assistance with the laboratory testing. Special thanks to the seven runners who cheerfully donated their time and bodily fluids to help progress our knowledge of fluid balance during exercise.

\section{References}

1 Grant SM, Green HJ, Phillips SM, Enns DL \& Sutton JR. Fluid and electrolyte hormonal responses to exercise and acute plasma volume expansion. Journal of Applied Physiology $1996 \mathbf{8 1}$ 2386-2392.

2 Hew-Butler T, Collins M, Bosch A, Sharwood K, Wilson G, Armstrong M, Jennings C, Swort J \& Noakes TD. Maintenance of plasma volume and serum sodium concentration despite body weight loss in ironman triathletes. Clinical Journal of Sport Medicine 200717 116-122.

3 Siegel AJ. Exercise-associated hyponatremia: role of cytokines. American Journal of Medicine 2006119 (Suppl 1) S74-S78.

4 Hew-Butler T, Jordaan E, Stuempfle KJ, Speedy DB, Siegel AJ, Noakes TD, Soldin SJ \& Verbalis JG. Osmotic and non-osmotic regulation of arginine vasopressin during prolonged endurance exercise. Journal of Clinical Endocrinology and Metabolism 200893 2072-2078.

5 Wade CE. Response, regulation, and actions of vasopressin during exercise: a review. Medicine and Science in Sports and Exercise 1984 16 506-511.

6 Luger A, Deuster PA, Debolt JE, Loriaux DL \& Chrousos GP. Acute exercise stimulates the renin-angiotensin-aldosterone axis: adaptive changes in runners. Hormone Research 198830 5-9.

7 Landgraf R, Hacker R \& Buhl H. Plasma vasopressin and oxytocin in response to exercise and during a day-night cycle in man. Endokrinologie 198279 281-291.

8 Mudambo KS, Coutie W \& Rennie MJ. Plasma arginine vasopressin, atrial natriuretic peptide and brain natriuretic peptide responses to long-term field training in the heat: effects of fluid ingestion and acclimatization. European Journal of Applied Physiology and Occupational Physiology 199775 219-225.

9 Deuster PA, Singh A, Hofmann A, Moses FM \& Chrousos GC. Hormonal responses to ingesting water or a carbohydrate beverage during a $2 \mathrm{~h}$ run. Medicine and Science in Sports and Exercise $1992 \mathbf{2 4} 72-79$.

10 Scrimgeour AG, Noakes TD, Adams B \& Myburgh K. The influence of weekly training distance on fractional utilization of maximum aerobic capacity in marathon and ultramarathon runners. European Journal of Applied Physiology and Occupational Physiology $198655202-209$.

11 Verbalis JG, McHale CM, Gardiner TW \& Stricker EM. Oxytocin and vasopressin secretion in response to stimuli producing learned taste aversion in rats. Behavioral Neuroscience $1986100466-475$.

12 Guo T, Taylor RL, Singh RJ \& Soldin SJ. Simultaneous determination of 12 steroids by isotope dilution liquid chromatography-photospray ionization tandem mass spectrometry. Clinica Chimica Acta $2006 \mathbf{3 7 2} 76-82$. 
13 Soldin SJ, Soldin OP, Boyajian AJ \& Taskier MS. Pediatric brain natriuretic peptide and N-terminal pro-brain natriuretic peptide reference intervals. Clinica Chimica Acta $2006366304-308$.

14 Vieweg WV, Godleski LS Graham Pet al. The link between fluid intake and weight gain in psychosis. Psychosomatics 199132 52-57.

15 Convertino VA, Keil LC \& Greenleaf JE. Plasma volume, renin, and vasopressin responses to graded exercise after training. Journal of Applied Physiology $1983 \mathbf{5 4}$ 508-514.

16 Maughan RJ, Shirreffs SM \& Leiper JB. Errors in the estimation of hydration status from changes in body mass. Journal of Sports Sciences 200725 797-804.

17 Verbalis JG. Disorders of body water homeostasis. Best Practice and Research. Clinical Endocrinology and Metabolism 200317 471-503.

18 Inder WJ, Hellemans J, Swanney MP, Prickett TC \& Donald RA. Prolonged exercise increases peripheral plasma ACTH, CRH, and AVP in male athletes. Journal of Applied Physiology $1998 \mathbf{8 5}$ 835-841.

19 Duclos M, Corcuff JB, Pehourcq F \& Tabarin A. Decreased pituitary sensitivity to glucocorticoids in endurance-trained men. European Journal of Endocrinology 2001144 363-368.

20 Petrides JS, Gold PW Mueller GP et al. Marked differences in functioning of the hypothalamic-pituitary-adrenal axis between groups of men. Journal of Applied Physiology 199782 1979-1988.

21 Chiodera P, Volpi R Maffei ML et al. Role of GABA and opioids in the regulation of the vasopressin response to physical exercise in normal men. Regulatory Peptides 199349 57-63.

22 Deuster PA, Faraday MM, Chrousos GP \& Poth MA. Effects of dehydroepiandrosterone and alprazolam on hypothalamic-pituitary responses to exercise. Journal of Clinical Endocrinology and Metabolism 200590 4777-4783.

23 Conrad KP, Gellai M, North WG \& Valtin H. Influence of oxytocin on renal hemodynamics and sodium excretion. Annals of the New York Academy of Sciences 1993689 346-362.

24 Cross RB, Dicker SE, Kitchin AH, Lloyd S \& Pickford M. The effect of oxytocin on the urinary excretion of water and electrolytes in man. Journal of Physiology 1960153 553-561.

25 Chicharro JL, Hoyos J, Bandres F, Gomez GF, Perez M \& Lucia A. Plasma oxytocin during intense exercise in professional cyclists. Hormone Research 200155 155-159.

26 Altemus M, Roca C, Galliven E, Romanos C \& Deuster P. Increased vasopressin and adrenocorticotropin responses to stress in the midluteal phase of the menstrual cycle. Journal of Clinical Endocrinology and Metabolism $2001862525-2530$.

27 Williams TD, Abel DC, King CM, Jelley RY \& Lightman SL. Vasopressin and oxytocin responses to acute and chronic osmotic stimuli in man. Journal of Endocrinology $1986 \mathbf{1 0 8} 163-168$.
28 Thomson WB. The effect of oxytocin and vasopressin and of phenylalanyl 3-oxytocin on the urinary excretion of water and electroytes. Journal of Physiology 1960150 284-294.

29 Kostoglou-Athanassiou I, Treacher DF \& Forsling ML. Is oxytocin natriuretic in man? Journal of Endocrinology 199414339.

30 Abdul-karim R \& Assali NS. Renal function in human pregnancy. V. Effects of oxytocin on renal hemodynamics and water and electrolyte excretion. Journal of Laboratory and Clinical Medicine $196157522-532$.

$31 \mathrm{Li} \mathrm{C,} \mathrm{Wang} \mathrm{W} \mathrm{Summer} \mathrm{S} \mathrm{et} \mathrm{al.} \mathrm{Molecular} \mathrm{mechanisms} \mathrm{of}$ antidiuretic effect of oxytocin. Journal of the American Society of Nephrology 200819 225-232.

32 Huang WS, Lee MS, Perng HW, Yang SP, Kuo SW \& Chang HD. Circulating brain natriuretic peptide values in healthy men before and after exercise. Metabolism 200251 1423-1426.

33 Scharhag J, Urhausen A Schneider G et al. Reproducibility and clinical significance of exercise-induced increases in cardiac troponins and N-terminal pro brain natriuretic peptide in endurance athletes. European Journal of Cardiovascular Prevention and Rehabilitation 200613 388-397.

34 Staessen J, Fagard R, Hespel P, Lijnen P, Vanhees L \& Amery A. Plasma renin system during exercise in normal men. Journal of Applied Physiology 198763 188-194.

35 Vanoverschelde JL, Younis LT Melin JA et al. Prolonged exercise induces left ventricular dysfunction in healthy subjects. Journal of Applied Physiology 1991 70 1356-1363.

36 Shor R, Rozenman Y Bolshinsky A et al. BNP in septic patients without systolic myocardial dysfunction. European Journal of Internal Medicine 200617 536-540.

37 Hutchens MP \& Weinmann M. Renal protection with recombinant b-type natriuretic peptide in a burn patient with rhabdomyolysis. Burns $200632128-131$.

38 Moro C, Galitzky J, Sengenes C, Crampes F, Lafontan M \& Berlan M. Functional and pharmacological characterization of the natriuretic peptide-dependent lipolytic pathway in human fat cells. Journal of Pharmacology and Experimental Therapeutics 2004 308 984-992.

39 Viru A, Karelson K \& Smirnova T. Stability and variability in hormonal responses to prolonged exercise. International Journal of Sports Medicine 199213 230-235.

40 Raubenheimer PJ, Young EA, Andrew R \& Seckl JR. The role of corticosterone in human hypothalamic-pituitary-adrenal axis feedback. Clinical Endocrinology $2006 \mathbf{6 5} 22-26$.

Received 23 July 2008

Accepted 12 September 2008 